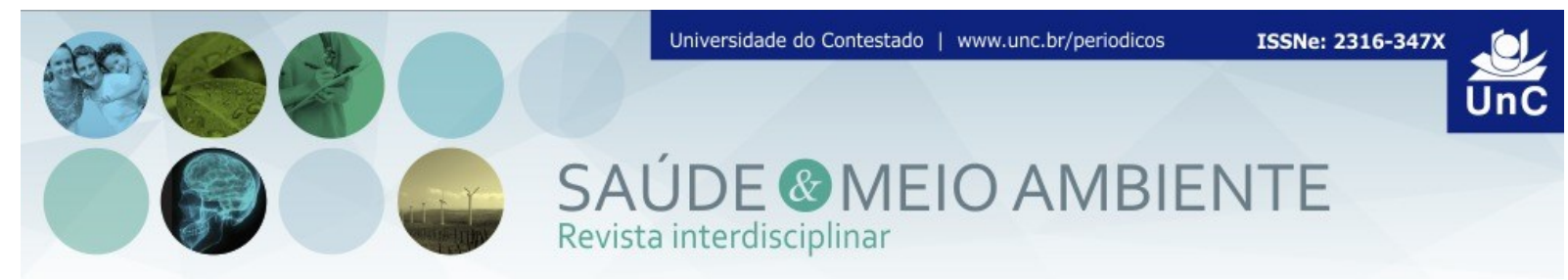

\title{
O ENTENDIMENTO DA MORTE PARA PROFISSIONAIS DE SAÚDE DE UM HOSPITAL GERAL DE SANTA CATARINA
}

\author{
Pollyana Weber da Maia Pawlowytsch ${ }^{1}$
}

Edinara Kovalski ${ }^{2}$

\begin{abstract}
RESUMO
Com o decorrer do tempo na cultura ocidental, o tema de morte é vista pela sociedade com preconceito, onde muitas pessoas encontram dificuldades de se falar sobre esse assunto. Os profissionais de saúde que trabalham diariamente com a possibilidade de morte encaram-na como um resultado não desejado diante do objetivo de sua profissão, que é a busca da saúde e a cura das doenças. Se sentem frequentemente responsáveis pela manutenção da vida de seus pacientes, que muitas vezes encontram-se gravemente enfermos gerando situações acompanhadas de grande sofrimento, provocando em muitos deles sentimentos de impotência, culpa em relação à perda dos pacientes. Este estudo buscou compreender e refletir sobre a importância e a necessidade dos profissionais terem conhecimento sobre o tema de morte e o processo de morrer. Participaram do estudo 13 técnicos de enfermagem de ambos os gêneros, com idade entre 23 e 54 anos, atuando profissionalmente na clínica médica de um Hospital Geral. Como principais dados identificados na análise do conteúdo das verbalizações dos participantes identificou-se sentimento de compaixão e impotência, frente ao processo de morte. Com relação à percepção do processo de morrer, identificou-se que os profissionais a compreendem como um ciclo natural da vida. Através da análise das entrevistas dos profissionais foi possível identificar a necessidade da preparação emocional dos mesmos, frente aos sentimentos vivenciados por estes durante o processo de morrer de seus pacientes e da dificuldade de trabalhar esta temática com os familiares.
\end{abstract}

Palavras Chaves: Psicologia Hospitalar. Processo de Morrer. Enfermagem.

\footnotetext{
${ }^{1}$ Mestre em Desenvolvimento Regional pela Universidade do Contestado. Professora Titular da Universidade do Contestado Campus Mafra, Santa Catarina. Brasil. E-mail: pollyana@netuno.com.br

2Especialização em Gestão de Pessoas pela Universidade Candido Mendes. Psicóloga do Hospital São Vicente de Paulo. Santa Catarina. Brasil. E-mail: psicologa edinara@hotmail.com
} 


\title{
THE UNDERSTANDING OF DEATH FOR HEALTH PROFESSIONALS IN A GENERAL HOSPITAL OF SANTA CATARINA
}

\begin{abstract}
With the passage of time in Western culture, the theme of "death" is taking more the idea of something "unnatural", seen by society with prejudice, as something unpronounceable or as if I did not need to think. Health professionals who work daily with the possibility of death face it as a result unwanted front of goal of their profession, which is the pursuit of health and the cure of diseases. They often feel responsible for the maintaining life of their patients, who often are critically ill generating situations accompanied by great suffering, therefore causing many of them feelings of helplessness, guilt over the loss of patients. This study tried to understand and reflect on the importance and the necessity of having professional knowledge about "death" and the dying process. The study included 13 nursing technicians of both genders, aged between 23 and 54 years, working professionally in the medical clinic of a General Hospital. Main data identified in the content analysis of verbalizations of the participants identified themselves feeling of compassion and helplessness, front the dying process. In relation the perception of the dying process, it was identified that professionals understand it as a natural cycle of life. By analysis of interviews with professionals were able to identify the need for emotional preparation thereof, front of the feelings experienced by them during the dying process of their patients and the difficulty of working with this theme family.
\end{abstract}

Keywords: Hospital Psychology. Dying Process. Nursing.

\section{INTRODUÇÃO}

A morte é um dos mais antigos temas, que sempre despertou ampla variedade de emoções e atitudes que remetem geralmente ao medo, à angústia ou à rejeição. $E$ é muitas vezes vinculada com o sobrenatural, o terror, o castigo, a dor, entre outros significados considerados negativos pela sociedade ocidental (ARIÈS, 2012).

A vida como finitude é singular para cada indivíduo e para cada cultura. A morte biológica nem sempre é a mais temida, mas o abandono, a separação, a dor psíquica, assim como a física, marcam tanto a vida quanto as perdas irreparáveis. Com o decorrer do tempo na cultura ocidental, a compreensão do tema de morte vem assumindo cada vez mais a ideia de algo "não natural", vista pela sociedade com preconceito, como algo impronunciável ou como se não se fizesse necessário pensar (FISCHER, 2007).

Assim, é neste contexto com relação à morte que se encontra o profissional da saúde, pois cotidianamente permanece em conflito, lutando pela vida e contra a morte, tomando para si a responsabilidade de salvar, curar ou aliviar, procurando preservar a vida, já que a morte, na maioria das vezes, é vista por estes profissionais como 
fracasso, sendo incessantemente combatida, como se fosse responsabilidade de alguém da equipe hospitalar impedi-la (KOVÁCS, 2012).

Segundo Fischer (2007), a diferença entre as pessoas em geral e os profissionais da área da saúde, médicos, enfermeiros e psicólogos, é que a morte faz parte do seu cotidiano e pode se tornar companheira de trabalho diária, onde estes profissionais tem a possibilidade diariamente de se deparar com ela. Dessa maneira vê-se a importância do conhecimento do tema de morte não somente para equipe de enfermagem, mas para toda a equipe multidisciplinar em que estão envolvidas neste contexto.

A partir desta condição de multidisciplinaridade vê-se a psicologia como ciência, reflexão e prática que cuida das questões do homem, das suas relações com os outros, com o mundo e consequentemente com a vida e a morte. Sendo assim, é de suma importância o psicólogo refletir e questionar sobre este tema, buscando conhecimento para trabalhar com este assunto que é muito presente no cotidiano de diversas áreas de atuação, em especial aos profissionais da saúde, provocando em muitos deles sentimentos de impotência e culpa em relação à perda dos pacientes (KOVÁCS, 2013).

No hospital, onde se prioriza a vida e a busca em salvar o paciente de alguma forma, a ocorrência de morte, pode fazer com que o trabalho da equipe seja encarado como frustrante, desmotivador e sem significado. Da mesma forma, não conseguir evitar ou adiar a morte ou não conseguir aliviar o sofrimento, pode trazer ao profissional, sentimentos de impotência, podendo ser algo extremamente doloroso (KOVÁCS, 2012). Pensando na necessidade de amenizar o sofrimento de quem passa por esse processo e preparar profissionais sobre a condição de que a morte faz parte do dia-a-dia de trabalho, é que surge a ciência que estuda a morte e o processo de morrer, denominada de Tanatologia.

A Tanatologia tem como objetivo o estudo da morte e os processos de morrer incluindo as perdas e luto. Ela busca preparar e auxiliar as pessoas para tais processos que fazem parte do desenvolvimento humano. Aliviando dessa maneira a dor psíquica e o sofrimento de quem convive ou trabalha no ambiente no qual a morte está presente (FISCHER, 2007).

Segundo França e Batomé (2005), a palavra morte traz consigo muitos atributos e associações: dor, ruptura, interrupção, desconhecimento, tristeza. Designa o fim absoluto de um ser humano; coexiste com a vida o que não a impede de ser angustiante e causar medo.

Para Morin (1970), a morte está presente durante a vida toda, pode ser identificada em grande parte das religiões, quando demonstra a busca pela transcendência e sentido na superação da finitude humana diante do mistério da vida. Dessa maneira, é possível compreender que a morte mesmo fazendo parte do desenvolvimento humano, sempre despertou sentimento de medo nas pessoas diante da mesma.

Do ponto de vista psicológico, Kübler-Ross (2000), descreve que o homem passa a se defender de vários modos contra o medo crescente da morte e contra a 
incapacidade de prevê-la e se proteger da mesma, em nosso inconsciente não podemos conceber nossa própria morte, mas acreditamos na nossa imortalidade.

Já para Leite e Machado (2006), o medo da morte como processo de morrer, representa para o homem, um sentimento de separação, de desaparição de si mesmo e de fracasso, por isso as pessoas procuram evitá-la.

A vida é sempre vista separada da morte. A morte é vista como um fracasso em não poder evitá-la, com isso há o esquecimento de que a partir do momento em que se nasce, tem-se idade suficiente para morrer, pois que a vida e a morte chegam juntas ao mundo. Desta forma faz-se a representação de morte com temor da mesma, como se fosse possível eliminá-la da vida (ARAÚJO; VIEIRA, 2004).

Os profissionais de saúde que trabalham diariamente com a possibilidade de morte encaram-na como um resultado acidental diante do objetivo de sua profissão, que é a busca da saúde e a cura das doenças. Se sentem muitas vezes responsáveis pela manutenção da vida de seus pacientes, gerando situações acompanhadas de grande sofrimento. Neste caso a morte é considerada como um insucesso no tratamento e um fracasso da equipe, provocando sentimentos de angústia àqueles que a presenciam (ARAÚJO; VIEIRA, 2004).

Para Kovács (2012), a equipe de enfermagem, acaba tendo contato maior com os familiares que acompanham este processo e que estão vivendo situações de ansiedade e desespero diante do sofrimento e da possível perda de seu familiar. Esta família muitas vezes busca respostas, querem confirmação da esperança de cura. $E$ o contato com estas demandas familiares provoca nesta equipe, sobrecarga frente ao fato de que além de ter muitas outras atividades a serem realizadas frente ao cuidado, não se encontra preparada emocionalmente para lidar com este contexto familiar.

Sendo assim, se torna algo indispensável dentro do ambiente hospitalar, que os profissionais de saúde tenham esse conhecimento de forma que se sintam preparados para atuarem no contexto do processo de morte. Frente ao que foi descrito, este estudo buscou conhecimento sobre qual a compreensão que os profissionais de saúde de um Hospital Geral de Santa Catarina possuem sobre a morte.

Este estudo justifica-se pela ausência de conhecimento da temática que envolve a morte e o processo de morrer na formação dos profissionais de saúde, bem como os sentimentos vivenciados e as dificuldades encontradas em trabalhar esta questão; a qual envolve equipe, paciente e os familiares que o acompanham. Os profissionais de enfermagem como todo ser humano, tem suas tristezas, irritações, receio da morte dentre outros sentimentos, devendo procurar na medida do possível, tornar estas tensões mínimas, assegurando que suas respostas individuais não prejudiquem o paciente e seus familiares (PIMENTEL et al, 1978). 


\section{METODOLOGIA}

Trata-se de um estudo de natureza básica, descritiva, explicativa de abordagem qualitativa. A amostra do estudo foi composta por 13 técnicos de enfermagem, alocados na clínica médica de um Hospital Geral de Santa Catarina. Para a coleta de dados foi realizada a entrevista estruturada a fim de levantar os dados propostos neste estudo. A coleta de dados ocorreu entre os meses de agosto e setembro de 2014, mediante entrevista previamente agendada, realizada individualmente, em local reservado, na unidade de atuação dos profissionais que aceitaram participar do estudo, assinando o termo de consentimento livre e esclarecido. Para a averiguação dos dados foi utilizada a análise de conteúdo de Laurence Bardin. Este estudo foi encaminhado ao Comitê de Ética em Pesquisa da Universidade do Contestado e obteve parecer de aprovação N 669.135.

\section{RESULTADOS E DISCUSSÃO}

Participaram do estudo 13 profissionais técnicos em enfermagem, destes eram $76,93 \%$ do gênero feminino e $23,07 \%$ do gênero masculino. Em análise da idade dos participantes $38,46 \%$ possuem idade de 18 até 25 anos, 15,38\% possuem idade de 26 até 33 anos, 23,07\% possuem idade de 34 até 41 anos e 23,07\% possuem acima de 42 anos. O quadro abaixo demonstra esta distribuição numérica.

Outro dado identificado foi o tempo em que os profissionais participantes do estudo atuam na unidade de clínica médica do hospital, sendo que 15,38\% atuam nesta unidade há mais de 12 anos, $0 \%$ dos participantes do estudo atuam nesta unidade em um período de 6 a 11 anos e $84,61 \%$ dos participantes atuam nesta unidade menos de 5 anos. O tempo em que se executa as rotinas de trabalho muitas vezes influencia na forma de como administramos as situações rotineiras de nossa atividade de trabalho (CHIAVENATO,1999). Desta forma é válido considerar que 11 dos 13 profissionais participantes do estudo desenvolvem atividades de técnicos de enfermagem na unidade de clínica médica deste hospital num período inferior há 5 anos.

Buscando atender o objetivo central deste estudo foi realizada uma entrevista com todos os participantes e os discursos destes possibilitaram a construção do quadro 1. 
Quadro 1 - Tabela de Bardin demonstrando a análise realizada nos discursos coletados nas entrevistas.

\begin{tabular}{|c|c|c|}
\hline Categoria & Subcategoria & Elementos de Análise \\
\hline \multirow[t]{2}{*}{ Significado da Morte } & Positivo & Fim do sofrimento do paciente \\
\hline & Negativo & $\begin{array}{l}\text { Inicio do sofrimento de Perda para } \\
\text { a Família }\end{array}$ \\
\hline $\begin{array}{l}\text { Percepção do Profissional } \\
\text { sobre o processo de morrer } \\
\text { de seu paciente }\end{array}$ & Positiva & Processo natural do ciclo de vida \\
\hline \multirow{2}{*}{$\begin{array}{l}\text { Sentimentos vivenciados } \\
\text { pelos Profissionais }\end{array}$} & Positivo & Compaixão \\
\hline & Negativo & Impotência \\
\hline \multirow{4}{*}{$\begin{array}{l}\text { Estratégias utilizadas pela } \\
\text { equipe para trabalhar com a } \\
\text { situação de morte de seu } \\
\text { paciente. }\end{array}$} & \multirow[t]{2}{*}{ Positivas } & Espiritualidade \\
\hline & & Equilíbrio Profissional \\
\hline & \multirow[t]{2}{*}{ Negativas } & Desapego \\
\hline & & Frieza \\
\hline
\end{tabular}

$\mathrm{Na}$ construção do quadro de Bardin realizada a partir dos discursos coletados em entrevista, foi possível determinar 4 categorias, 7 subcategorias e 09 elementos de análise. A primeira categoria é representada pelo significado da morte para os profissionais participantes do estudo, esta categoria determinou duas subcategorias positiva e negativa. A subcategoria denominada como significado positivo apresentou o fim do sofrimento ao paciente como elemento de análise, este elemento pode ser explicado quando os profissionais que acompanham os pacientes no processo de morrer acabam encarando a morte como o fim do sofrimento de seus pacientes e isso é verificado nas falas dos profissionais a partir do discurso do sujeito 12 quando verbaliza (SIC) "É o fim de um sofrimento, porque tem muitas pessoas que se encontram sofrendo muito, a morte vem ser o alívio [...], e no discurso do sujeito 10 quando (SIC) "O fim da vida é onde acaba o sofrimento [...]". Para Mota et. al. (2011), compreender a morte como a solução da dor, da angústia e de todo o processo que envolve o morrer é uma maneira que os profissionais encontram para se proteger do sofrimento psíquico decorrente da perda do paciente.

Ainda dentro da categoria representada pelo significado da morte, a segunda subcategoria encontrada foi o significado negativo, que apresentou como elemento de análise o início do sofrimento advindo da perda para a família, neste elemento observa-se que os profissionais se sentem comovidos pela dor da perda que o familiar está vivenciando. Este sentimento pode ser identificado na fala do sujeito 11 quando verbaliza: (SIC) "É muito sofrido para a família que fica [...]". Para Shimizu (2007), o grau de sofrimento normalmente é intensificado de acordo com o tipo de vínculo estabelecido pela equipe de enfermagem entre paciente e os familiares envolvidos. Muitos profissionais ainda sentem essa perda de forma tão acentuada, que é como se o paciente fosse algum membro de sua família.

A segunda categoria é representada pela percepção do profissional sobre o processo de morrer de seu paciente, a qual determinou a subcategoria percepção 
positiva que possibilita a análise de um único elemento presente, sendo o processo natural do ciclo de vida.

No elemento de análise processo natural do ciclo de vida, os profissionais descrevem a morte como um processo natural do ciclo de vida, pelo qual todos os seres humanos irão passar. Dessa maneira isso possibilita para os profissionais uma melhor aceitação da morte de seus pacientes. Isso pode ser identificado nas falas dos profissionais a partir do discurso do sujeito 12 quando verbaliza (SIC) "É uma situação normal, natural dentro de uma realidade prescrita [...]", e no discurso do sujeito 13 quando verbaliza (SIC) "A morte e o morrer é algo corriqueiro, é parte do meu dia-adia então ela é normal [...]".

Para Ribeiro, Baraldi e Silva (1998), pensando na morte em seu aspecto biológico e racional é fácil fazer seu diagnóstico como um acontecimento que completa o ciclo que é de nascer, crescer, envelhecer e morrer. Porém, quando ela ocorre não está desprovida de contextos emocionais, por representar o rompimento de um vínculo com alguém que se goste ou não, que não mais fará parte dos vivos.

A terceira categoria representada pelos sentimentos vivenciados pelos profissionais determinou duas subcategorias; sendo positiva que determinou 0 elemento de análise compaixão e a subcategoria negativa que determinou o elemento de análise impotência.

Quanto ao primeiro elemento de análise compaixão, percebe-se que os profissionais sentem: cuidado, atenção e solidariedade pelos familiares enlutados, compartilhando dos sentimentos vivenciados por estes. Como podemos identificar nas falas dos profissionais a partir do discurso do sujeito 01 quando verbaliza (SIC) "Perda, compaixão das pessoas que ficam: dos familiares e amigos [...]", e no discurso do sujeito 03 quando verbaliza (SIC) "A gente compartilha junto os sentimentos, da dor que a família sente em perder alguém [...]".

Segundo Gutierrez e Ciampone (2006), a relação entre prazer e sofrimento no trabalho dos profissionais de enfermagem, evidencia que esses profissionais valorizam a necessidade de demonstrar afeto e dedicação ao lidar com a dor e o sofrimento do paciente e de seus familiares, como algo que confere significado ao trabalho, polarizando o prazer na realização das atividades inerentes ao cuidar.

Já na segunda subcategoria, representada pelo elemento de análise impotência, permite-nos identificar que os profissionais verbalizam sentimentos de impotência diante do processo de morrer de seus pacientes, isso se deve ao fato que os profissionais de saúde carregam a responsabilidade da cura das doenças e a manutenção da vida de seus pacientes, dessa maneira, o não conseguir evitar a morte gera tal sentimento de impotência. Como podemos identificar nas falas dos profissionais a partir do discurso do sujeito 01 quando verbaliza (SIC) "Não poder ajudar mais o paciente, não chegar ao resultado esperado que seria a recuperação do paciente, me faz sentir impotente [...]"; também no discurso do sujeito 03 quando verbaliza (SIC) "Sensação de falta, de que poderia ter sido feito mais pela equipe, para tentar ajudar o paciente, isso me faz sentir impotente perante mim, a equipe e os 
familiares [...]"; e no discurso do sujeito 12 quando verbaliza (SIC) "Tenho sentimento de Impotência, vontade de ajudar mais, para que eles permaneçam vivos [...]".

Segundo Silva e Ruiz (2003), é explicável, em algumas instâncias, o fato dos profissionais sentirem-se impotentes diante da perda de um paciente que está sendo assistido. Esse "fracasso" não se traduz somente como um fracasso nos cuidados empreendidos, mas como uma derrota diante da morte e da missão implícita das profissões em saúde: salvar o indivíduo, minimizar sua dor e seu sofrimento, trazê-lo à vida.

A quarta categoria é representada pelas estratégias utilizadas pela equipe para trabalhar com a situação de morte de seu paciente e determinou duas subcategorias sendo estas: positiva representada pelos elementos de análise espiritualidade e equilíbrio profissional e a subcategoria negativa representada pelos elementos de desapego, frieza.

No primeiro elemento de análise que se refere à espiritualidade, identifica-se que os profissionais utilizam esta estratégia como um fator que lhes dê amparo nas situações que envolvem a morte e o processo de morrer, gerando certo conforto emocional. Como pode ser identificado nas falas dos profissionais a partir do discurso do sujeito 07 quando verbaliza (SIC) "Busco conhecimento espiritual [...]"; e no discurso do sujeito 01 quando verbaliza (SIC) "Procuro rezar, isso me ajuda a seguir em frente sem me abalar [...]".

Para Silva e Ruiz (2003), a religião e espiritualidade nesse sentido, parecem funcionar como um ansiolítico diante da morte e do processo de morrer. Torna a morte apenas um fato, de certa maneira, gerando com isso uma tranquilidade nos profissionais que convivem diariamente com a morte e o processo de morrer.

Ainda dentro da categoria representada pelas estratégias utilizadas pela equipe, para trabalhar com a situação de morte de seu paciente, na subcategoria positiva, que possui como elemento de análise o equilíbrio profissional, verifica-se que os profissionais mesmo em momentos em que acompanham o processo de morrer de seus pacientes buscam manter o equilíbrio profissional de maneira que este momento seja o menos doloroso, tanto para familiares quanto para eles mesmos. Isso pode ser identificado nas falas dos profissionais a partir do discurso do sujeito 08 quando verbaliza (SIC) "Mantenho a calma e tento confortar o paciente [...]"; também no discurso do sujeito 10 quando verbaliza (SIC) "Passar tranquilidade para a família e para o paciente, isso faz parte do meu trabalho, tenho que ser profissional nesta hora [...]"; e no discurso do sujeito 09 quando verbaliza (SIC) "Procuro a compreensão do caso, estudo da patologia[...]".

Segundo Fischer et al, (2007, p. 6).

Trabalhar numa instituição hospitalar se configura em assistir o outro, em colaborar, em cuidar. Assim, para lidar com as dores, ansiedades, angústias, medos e sofrimentos dos pacientes, para conviver com o desespero, a revolta e a incompreensão dos familiares, é preciso que a equipe tenha respaldo de um trabalho psicológico capaz de oferecer o suporte emocional necessário (FISCHER et al, 2007, p. 6). 
Ainda dentro da categoria representada pelas estratégias utilizadas pela equipe para trabalhar com a situação de morte de seu paciente, na subcategoria negativa, ao se analisar o elemento desapego, identifica-se que os profissionais usam como forma de defesa para poder enfrentar o processo de morrer de seus pacientes, não se apegar aos mesmos. Isso pode ser verificado no discurso do sujeito 05 quando verbaliza (SIC) "Procuro não me apegar ao paciente [...]". Spíndola e Macedo (1994), afirmam que a insensibilidade aparente do profissional, ao vivenciar mais uma perda, significa um mecanismo de defesa utilizado com o fim de "suportar" a situação cotidianamente.

Já no elemento de análise (ainda dentro desta mesma subcategoria) que se refere à frieza, identifica-se que os profissionais tentam não se envolver com o paciente como uma forma de proteção dos seus sentimentos, utilizando dessa estratégia como uma maneira encontrada para poder lidar com este processo. Isso fica claro na fala do sujeito 11 quando verbaliza (SIC) "Procuro me mostrar da forma mais fria possível para não me afetar, uso isso como uma defesa para mim [...]."

Silva, Ribeiro e Kuse (2009), descrevem que o profissional internaliza a crença de que seus sentimentos devem ser contidos perante o paciente, desse modo é construída uma atitude frente à morte, a qual o profissional que tem a propensão de se mostrar "frio" ou indiferente no processo de morrer de seus pacientes, uma vez que acredita que reconhecer o seu sofrimento significa mostrar-se vulnerável, colocando em risco a preservação do princípio da boa técnica.

Desta forma é possível identificar no decorrer deste estudo que o processo de morrer do paciente provoca uma série de sentimentos no profissional de enfermagem, de forma que o mesmo procure buscar estratégias para elaborar demandas diárias desencadeadas pelas rotinas de seu trabalho.

\section{CONSIDERAÇÕES FINAIS}

Através deste estudo, pode ser identificada a rotina de trabalho dos profissionais de enfermagem quando relacionada ao processo de morte e de morrer, que provoca no grupo estudado sentimento de compaixão e empatia para com a família do paciente que acompanha este processo. A morte em alguns momentos é relatada pelos profissionais como um alívio e fim do sofrimento do paciente que é percebida como um processo natural do ciclo de vida. Também foi identificado que os profissionais apresentam sentimentos de tristeza e impotência frente ao fato de não conseguir evitar a morte de seus pacientes, na qual utilizam como defesa a espiritualidade e o equilíbrio profissional.

Segundo Kovács (2013), para os profissionais da área da saúde a morte faz parte do dia-a-dia de trabalho, porém estes profissionais encontram-se muitas vezes, despreparados e apresentam dificuldades para lidar com este processo, podendo indicar um despreparo do profissional para lidar com a morte de seu paciente no que se refere a questões emocionais. 
Através dos resultados deste estudo identificou-se a importância dos profissionais de saúde, os quais tem a morte como parte do seu cotidiano, terem um preparo psicológico, proporcionando a elaboração dos seus sentimentos que envolvem o medo, tristeza e angústia da equipe de saúde frente a esse processo. Tal preparo auxilia a equipe no melhor desempenho de suas funções como profissionais no trabalho, facilitando a interação de equipe, paciente e família.

Desta forma, conclui-se que existe a necessidade de serem discutidos assuntos sobre o tema de morte e o processo de morrer na formação dos profissionais de saúde na qual são preparados para a cura, esquecendo que a morte fará parte do seu cotidiano profissional de maneira que se sintam seguros e preparados ao terem que trabalhar frente a esta temática.

\section{REFERÊNCIAS}

ARIÈS, Philippe. História da morte no ocidente. Rio de Janeiro: Nova Fronteira, 2012.

ARAÚJO, Paula Vanêssa Rodrigues de. VIEIRA, Maria Jésia. A questão da morte e do morrer. Rev. Bras Enf. v. 57, n. 3, p. 361-363, maio/jun. 2004. Disponível em: <http://www.scielo.br/pdf/reben/v57n3/a22v57n3.pdf> Acesso em: 06 out. 2014.

CHIAVENATO, Idalberto. Administração de recursos humanos: fundamentos básicos. 4,ed. São Paulo: Atlas, 1999.

FISCHER, Joyce Maria Kolinsliet AL. Manual de tanatalogia. Curitiba: Conselho Federal de Psicologia do Paraná, 2007. Ed. Unificado. Disponível em:

<http://crppr.org.br/download/159.pdf> Acesso em: 18 de outubro de 2014.

FRANÇA, Maria Dulce. BATOME, Silvio Paulo. É possível uma educação para morte? Psicol. estud. v.10, n. 3. p. 547-548, 2005. Disponível em:

<file:///C:/Users/edy/Desktop/1.2014\%20novo/TCC\%20Artigos/\%C3\%89\%20possivel \%20educao\%20p\%20morte.pdf>. Acesso em: 20 set. 2014.

GUTIERREZ, Beatriz Aparecida Ozello. CIAMPONE, Maria Helena Trench. Profissionais de enfermagem frente ao processo de morte em unidades de terapiaintensiva. Acta Paul Enferm. 2006.

KOVÁCS, Maria Júlia. Educação para a morte: Desafios na formação de profissionais de saúde e educação. São Paulo: Casa do psicólogo. FAPESP, 2012.

KOVÁCS, Maria Júlia. Morte e desenvolvimento humano. São Paulo: Casa do psicólogo, 2013.

KÜBLER-ROSS, Elisabeth. Sobre a morte e o morrer. 8.ed. São Paulo: Martins Fontes. 2000. 
LEITE, Joséte Luzia; MACHADO, Willian César Alves. Eros e Thanatos: a morte sob a óptica da enfermagem. São Caetano do Sul, SP: Yendis, 2006.

MORIN, Edgar. O homem e a morte. 2. ed. Lisboa: Europa-América, 1970.

MOTA, Marina Soares et al. Reações e sentimentos de profissionais daenfermagem frente à morte dos pacientes sob seus cuidados. Rev. Gaúcha Enferm., Porto Alegre, v. 32, n. 1, mar. 2011. Disponível em: <http://www.scielo.br/scielo.php? script=sci_arttext\&pid=S198314472011000100017\&lng=en\&nrm=iso>. Acesso em 25 set. 2014 .

PIMENTEL, Marcos Alfredo.et al. Amenizando a morte. Rev. Enfermagem. nov. dimens, v. 4, n 6, 1978.

SHIMIZU, Helena Eri. Como os trabalhadores de enfermagem enfrentam o processode morrer. Revista Brasileira de Enfermagem - REBEN. 2007. p. 257262.

SILVA, Karen Scheinda. RIBEIRO, Rubia Guimarães. KRUSE, Maria Henriqueta Luce. Discursos de enfermeiras sobre morte e morrer: vontade ou verdade?. Rev. bras. enferm. v. 62, n. 3, p. 451-456. 2009. Disponível em:

<http://dx.doi.org/10.1590/S0034>.

RIBEIRO, Maria Cecília; BARALDI, Solange; SILVA, Maria Júlia Paes da. A Percepção da equipe de enfermagem em situação de morte: ritual do preparo do corpo "pós-morte". Revista Escola de enfermagem da USP, v.32, n.2, p. 117-23, 1998.

SILVA, Antonio Lucieudo Lourenço. RUIZ, Erasmo Miessa. Cuidar, morte e morrer: significações para profissionais de Enfermagem. Estud. psicol. (Campinas). v. 20, n. 1, p. 15-25, 2003. Disponível em: <http://dx.doi.org/10.1590/S0103$166 \times 2003000100002>$.

SPÍNDOLA, Telma. MACEDO, Maria do Carmo dos Santos. A morte no hospital e seu significado para os profissionais. Revista Brasileira de Enfermagem, v.47. 1994.

Artigo recebido em: 03/03/2016

Artigo aprovado em: 15/11/2017

Artigo publicado em: 20/12/2017 